\title{
THE PARA-ARTICULAR OSSIFICATIONS IN OUR PARAPLEGICS AND TETRAPLEGICS: A SURVEY OF 704 PATIENTS
}

By A. M. Hernandez, M.D., ${ }^{1}$ J. V. Forner, M.D., D.Phys.Med.(Eng), ${ }^{2}$ T. DE LA Fuente, M.D., ${ }^{2}$ C. GonZalez, M.D. ${ }^{2}$ and R. Miro, M.D. ${ }^{2}$

${ }^{1}$ National Paraplegic Centre, Toledo; ${ }^{2}$ Hospital 'La Fe', Valencia, Spain

Abstract. The X-ray examination of 704 spinal cord injured patients have showed that in 20 per cent of the cases para-articular ossifications were present most frequently in the hips. They were less frequently found in non-traumatic and incomplete cases. No other clear relationship was found.

Key words: Ankylosis, Neurogenic ossifying fibromyopathy; Heterotopic ossification; Myositis ossificans circumscripta neurotica; Ectopic bone formation.

\section{Introduction}

IT Is well known that para-articular ossifications (PAO) are frequently found in spinal cord injured patients although there is a wide difference in frequency reported from author to author ranging from the 5 per cent reported by Guttmann (excluding the cases where local infection, pressure sores and fractures are present) to the $48 \cdot 7$ per cent reported by Dejerine and Ceillier (I9I9). As very little is known about the aetiology and pathophysiology, we are not able at present to explain this wide range of frequency.

As far as we know nothing has been published in Spain about the incidence of PAO in this country apart from the paper of Roig Escofet and Muntañola (I97I) that found I 4 cases of PAO in 30 paraplegics in Barcelona (46.67 per cent).

We feel that it could be interesting to study this problem in our patients making no attempt to draw conclusions about pathogenesis, as very little can be added to what has been said already.

\section{Material and Methods}

We have reviewed 704 patients admitted to the National Paraplegic Centre in Toledo (435 cases) and at the Spinal Unit of the La Fe Hospital in Valencia (269 cases). Some of the patients had been admitted initially to one of these Centres where the standard treatment is that followed in most Spinal Units but others had been transferred from different hospitals in Spain with great difference in the quality of the initial treatment. There is also a wide range in the age of these patients and in the time elapsed from the injury or disease which caused the spinal cord lesion.

The X-rays of these patients have been carefully examined in order to discover the presence of PAO regardless of its size or clinical symptoms. The cases where PAO were found around a fracture, a bone infection, a pressure sore or a fistula have been discarded. The number of patients with PAO was related to such parameters as the sex, age, aetiology level, completeness of the lesion and spasticity.

Afterwards the relative incidence of PAO in various joints was established and the $\chi^{2}$ test applied in order to examine the statistical significance. 


\section{Results and Discussion}

The number of patients with PAO found in our series was 143 giving an overall incidence of $20.3 \mathrm{I}$ per cent. This percentage is lower than the 48.7 per cent reported by Dejerine and Cellier (I9I9) the 4I per cent reported by Abramson and Kamberg (I949), the 40 per cent reported by Paeslack (I965) and the 27 per cent reported by Soulie (1927), but higher than the 17 per cent reported by Freehafer et al. (I966) and the 5 per cent reported by Guttmann (1976). It is similar to the 20 per cent reported by Wharton and Morgan (1970) and the I9 per cent by Scher (1976).

In our material we had 509 males ( 72 per cent) in which we found 106 cases of PAO (I 5 per cent) and I 95 females ( 28 per cent) in which we found 37 cases of PAO ( 5 per cent). If we compare the relative incidence in both sexes we find a 2I per cent of PAO in males and a 19 per cent in females. The incidence of PAO had therefore no relation with the sex.

Age

In our material the age distribution was as follows: 83 patients ( 12 per cent) were less than 20 years of age and seven of them had PAO (I per cent), 302 patients were between 20 and 40 years of age and 64 ( 9 per cent) had PAO, 209 were between 40 and 60 ( 30 per cent) years of age and 46 cases had PAO ( 7 per cent). The rest, that is I IO (20 per cent), were aged 60 years or more and we found 26 patients with PAO (44 per cent).

If we look at the relative incidence of patients with PAO in each group we find the following percentages: 8 per cent in the patients of less than 20 years of age, $2 \mathrm{I}$ per cent in the patients aged between $2 \mathrm{I}$ and 40 years, 22 per cent in those aged 4I to 60 years, 24 per cent in those of more than 60 years of age. Although it seems clear that the younger group has less cases of PAO than the older groups the difference is not statistically significant and there is no proof of any difference related to age. Nevertheless a single case of PAO in the patients of less than Io years of age was found in this study.

\section{Aetiology}

The aetiology of the spinal cord lesion of our patients was traumatic, tumoral, infectious, congenital, vascular, etc., but considering the relative high frequency and special features of the traumatic cases we have made two groups: traumatic with 394 patients ( 56 per cent) in which we found I02 patients with PAO (I4 per cent) and non-traumatic with 3 IO patients ( 44 per cent) with 4 I cases with PAO (6 per cent).

If we compare the relative incidence of cases with PAO in both groups we find that the 26 per cent of our traumatic patients developed PAO and only I 3 per cent of our non-traumatic. This difference is statistically significant although the reasons are not very clear. There are more incomplete lesions in the non-traumatic group of patients but the exact incidence has not been investigated.

\section{Level of the Lesion}

In our material we had 183 cervical patients ( 29 per cent) in which we found 37 cases with PAO ( 5 per cent), 366 thoracic lesions ( 52 per cent) with 80 cases of PAO (I I per cent), and I 55 patients with lumbar or cauda equina lesions ( 22 per cent) in which we found 26 cases of PAO (4 per cent).

Comparing the relative incidence of cases with PAO in each group we find 
that the 20 per cent of our cervical, the 22 per cent of our thoracic and in the I7 per cent of our lumbar or cauda equina patients develop this complication. Although in this last group the incidence is lower the difference is not statistically significant contrary to other authors who find a much lower incidence of PAO in low lesions.

\section{Completeness of the Lesion}

In our 27I patients with complete lesions ( 38 per cent) we found 89 with PAO ( 13 per cent) and in 433 with incomplete lesions we found 54 with PAO (8 per cent).

Comparing the relative incidence in both groups we find that 33 per cent of the patients with complete lesions develop PAO but only ( 12 per cent) of the incomplete lesions. This difference is statistically significant.

\section{Spasticity}

In our 538 spastic patients ( 76 per cent) we found Io9 with PAO (I 5 per cent) and in our I66 flaccid patients ( 24 per cent) we found 34 cases with PAO ( 5 per cent).

Comparing the relative incidence of PAO we find 20 per cent in our spastic cases and 20 per cent in our flaccid patients. Therefore there is no difference.

\section{Location of Osteomas}

In our I34 patients with PAO we found that in three cases they were located in the shoulders ( 2 per cent), in three cases in the elbows ( 2 per cent), in I33 in the hips ( 93 per cent) and in 20 patients in the knees (I4 per cent). Sometimes there was a double location, being in one case located in shoulder and knee ( $\mathrm{I}$ per cent) and in 15 cases in hip and knee (IO per cent). PAO were never found above the level of the spinal cord lesion.

Although the frequency of PAO in paraplegics is relatively high, only in I per cent of the cases were they severe enough to further impair functional activity.

\section{SUMMARY}

After examination of the X-rays of 704 patients we found the presence of para-articular ossifications in 143 cases ( 20 per cent). There was no relation with sex, level of the lesion or spasticity. It appeared less frequently in younger age groups but the difference was not statistically significant. It was less frequent in the non-traumatic cases and in the incomplete lesions; the difference being statistically significant. The main location of PAO was around the hips and they were never found above the level of spinal cord lesion.

\section{RÉSUMÉ}

L'étudié des radiographies correspondants aux 704 malades il a démontré la présence de O.P.A. dans I 43 des cases (20 per cent). N'est pas trouvé rapport avec le sexe, niveau de lésion ni spasticyté. Dans les malades plus jeunes, la fréquence il a eu moindre mais la différence n'eu pas statistiquement significatis. Aussi nos résultats ils out faire voir une fréquence plus petite dans les cases non traumatiques et dans les lésions médullaires incompletes. La localization tres important et nombreux il a eu autour des articulations des hanches et jamais par dessus de la lésion médullaire.

\section{ZUSAMMENFASSUNG}

Das Studium der Röntgenbilder von 704 Patienten erwies die Anwesenheit von PAO in I 43 Fällen (20 per cent). Man konnte keine Verhältnisse mit Sex, Beschädigung oder 'Spastizität' auffinden. Nicht so häufig wurden diese Ergebnisse in Jüngeren Patienten 
gefunden, aber der Unterschied war statistisch nicht bedeutend. Sehr wenig waren diese Ergebnisse in nicht traumatischen Fällen und unvollkommenen Verletzungen zu finden. Die Hauptlokalisierung von der Verknöcherung war rund um den Haften herum un niemals war sie über die Markverlezting nachzuweisen.

\section{REFERENCES}

ABRAMSON, A. \& KAMBERG, (I949). Spondylitis, pathological ossification and calcification associated with spinal cord injury. F. Bone and foint Surg., 3IA, 275-282.

DAMANSKI, M. (I96I). Heterotopic ossification in paraplegia: a clinical study. F. Bone and foint Surg., 43B, 286-299.

Dejerine, Mme. Cellier. A. \& Dejerine, Yv. (I9I9). Para-osteo-arthopaties des paraplegiques par lesion medullaire. Etude anatomique et histologique. Rev. Neurol., 26, 399-407.

FreeHAFER, A. A., YURICK, R. \& MAST, W. A. (1966). Para articular ossification in spinal cord injury. Med. Services f., 22, 47 I-478.

Guttmann, SIR L. (1976). Spinal Cord Injuries. Blackwell Scientific Publications, Oxford.

HARDY, A. G. \& DiCKSON, P. W. (I963). Pathological ossification in traumatic paraplegia, F. Bone and foint Surg., 45B, 76-87.

Liberson, M. (1953). F. Amer. Med. Assoc., 152, roio.

Paeslack, V. (I965). Intermisische Strungen bein. Paraplegiker, 59-60.

RoIg Escopet, D. \& MUNTAÑola, L. (I97I). Manifestaciones radiologicas de los parapléjicos y tetrapléjicos en la pelvis y en las estremidades inferiores. Med. Clin., 56, No. $5,669-680$.

SCHER, A. T. (1976). The incidence of ectopic bone formation in post-traumatic paraplegic patients of different racial groups. Paraplegia, 14, 202-206.

Stover, S. L., Hataway, C. J. \& ZeIgeR, H. E. (I975). Heterotopic ossification in spinal cord injured patients. Arch. Phys. Med. Rehabil., 56.

Wharton, G. W. \& Morgan, T. H. (1970). Ankylosis in paralyzed patient. F. Bone and foint Surg., A, I05-II2. 